\title{
Efeito de Diferentes Fontes Protéicas sobre Desempenho, Composição Corporal e Morfologia Intestinal em Leitões
}

\author{
Teresinha Marisa Bertol'1, Jorge Vítor Ludke ${ }^{1}$, Nelson Mores ${ }^{1}$
}

\begin{abstract}
RESUMO - Foi desenvolvido um estudo com o objetivo de avaliar o efeito da inclusão do leite desnatado em pó (LDP) em dietas de desmame contendo diferentes níveis de proteína concentrada de soja (PCS), para leitões desmamados aos 21 dias de idade. Foram comparadas cinco dietas, fornecidas do dia do desmame até 14 dias após: T1 - dieta testemunha, tendo o farelo soja (FS) como principal fonte protéica; T2 e T4 - substituição de 30 e 50\%, respectivamente, do FS da dieta testemunha por PCS; T3 e T5 - substituição de 30 e $50 \%$, respectivamente, do FS da dieta testemunha por PCS e $20 \%$ por LDP. A substituição parcial do FS por PCS em qualquer dos níveis testados, bem como a substituição de $20 \%$ do FS por LDP não influenciaram o desempenho nem a composição corporal ou a taxa de deposição de tecidos dos leitões em nenhum dos períodos avaliados. A altura da mucosa e a altura das vilosidades intestinais aos 14 dias após o desmame não foram afetadas pela fonte protéica da dieta, porém a profundidade da cripta foi reduzida nos leitões que receberam as dietas contendo PCS, independente da inclusão de LDP. A fonte protéica na dieta de desmame não afetou o desempenho nem a composição corporal dos leitões, mas a PCS proporcionou menor nível de alterações na morfologia da parede intestinal, indicado pela menor profundidade da cripta.
\end{abstract}

Palavras-chave: creche, desmame, fonte protéica, leite desnatado em pó, leitões, proteína concentrada de soja

\section{Effect of Different Sources of Protein on Performance, Body Composition and Intestinal Morphology of Piglets}

\begin{abstract}
A study was carried out to evaluate the effect of dried skim milk (LDP) in weaning diets containing different levels of high-protein soybean meal (PCS), for piglets weaned at 21 days of age. Five diets were compared, from weaning to 14 days postweaning: T1 - basal diet, soybean meal (FS) as the main protein source; T2 and T4 - replacement of 30 and $50 \%$, respectively, FS from basal diet by PCS; T3 and T5 - replacement of 30 and 50\%, of FS from basal diet by PCS and $20 \%$ by LDP, respectively. The partial replacement of FS by PCS or LDP did not affect the performance neither the body composition or deposition tissues ratios of piglets in anyone of the evaluated period. The mucous membrane height and villus height at 14 days post-weaning were not affected by the protein source of the diet, but crypt depth was reduced by PCS, regardless of diet supplementation with LDP. The protein source did not affect performance neither body composition of piglets, but PCS provided a reduction of morphologic changes of the intestinal mucous membrane, signed by the reduction of the crypt depth.
\end{abstract}

Key Words: dried skim milk, high-protein soybean meal, nursery phase, source of protein, piglets, weaning

\section{Introdução}

Grande variedade de ingredientes de origem vegetal ou animal, provenientes de diversos tipos de processamento, tem sido utilizada como fonte de energia e/ou proteína nas dietas pré-iniciais de leitões submetidos ao desmame precoce. O objetivo do uso destes ingredientes é o aumento da digestibilidade das dietas de desmame, adequando-as ao grau de amadurecimento do trato gastrointestinal, que varia com a idade e o peso dos leitões ao desmame. $\mathrm{O}$ alto $\mathrm{pH}$ estomacal (entre 3,8 e 4,3) nos leitões com menos de 35 dias de idade limita a proteólise gástrica, pois a pepsina gástrica é lentamen- te ativada em $\mathrm{pH} 4$ e rapidamente ativada em $\mathrm{pH} 2$ (WILSON e LEIBHOLZ, 1981). Dessa forma, leitões nesta faixa de idade têm sérias limitações para digerir proteínas de origem vegetal, porém digerem muito bem as proteínas do leite.

Entre os ingredientes utilizados em dietas para desmame, estão a proteína concentrada de soja (PCS), obtida a partir da soja integral, por meio de diferentes passos de processamento, resultando como produto final a proteína concentrada tradicional, proteína concentrada funcional ou proteína concentrada texturizada. A proteína concentrada texturizada de soja é obtida por intermédio de um conjunto de

\footnotetext{
1 Embrapa Suínos e Aves, Cx. Postal 21, CEP 89700-000, Concórdia, SC. E.mail: tbertol@cnpsa.embrapa.br; jorge@cnpsa.embrapa.br; mores@cnpsa.embrapa.br
} 
processamentos que envolve a extração do óleo, extração dos carboidratos solúveis através da lavagem do floco desengordurado com etanol e posterior extrusão (TURLINGTON et al., 1990a). Em função deste processamento, espera-se que a PCS seja um produto livre dos carboidratos indigestíveis, dos antígenos alérgicos e dos fatores antitrípticos encontrados na soja integral e em alguns outros subprodutos da soja. A extração dos carboidratos insolúveis com etanol melhora a qualidade da proteína da soja e reduz as alterações na morfologia intestinal provocadas por estas proteínas (HANCOCK et al., 1990a e b), além de evitar fermentações indesejáveis no intestino dos leitões. A extrusão dos subprodutos da soja melhora a digestibilidade do nitrogênio, desativa os inibidores da tripsina e reduz as propriedades antigênicas destes subprodutos por meio da desnaturação da matriz das proteínas antigênicas glicinina e $\beta$-conglicinina (FRIESEN et al., 1992; FRIESEN et al., 1993; e PARTRIDGE e GILL, 1993). Em algumas avaliações feitas com leitões, foi observada superioridade de 6,9 a $10,7 \%$ na digestibilidade da energia da PCS em relação à digestibilidade da energia do FS para leitões jovens após o desmame (BERTOL e LUDKE, 1999). O desempenho dos leitões desmamados aos 21 dias de idade também mostrou-se superior com a substituição de 50\% do FS da dieta pré-inicial por PCS em dietas isocalóricas (BERTOL et al., 1998).

O leite desnatado em pó (LDP) é outro subproduto utilizado em dietas para leitões, compondo dietas de transição para o desmame precoce, sendo um alimento de alta digestibilidade e com alto teor de energia. BERTOL e LUDKE (1999) observaram que a digestibilidade da energia do LDP foi 17,2 a $21,4 \%$ superior à digestibilidade da energia do FS e 9,7\% superior à digestibilidade da energia da PCS para leitões com idade entre 35 e 40 dias. TURLINGTON et al. (1989) observaram aumento de 5 a $10 \%$ na digestibilidade de dietas composta por subprodutos do leite (caseína e/ou lactose) em relação a dietas contendo somente produtos de origem vegetal (farelo de soja e/ou dextrose) para leitões entre 23 a 27 e 33 a 37 dias de idade. De acordo com os autores, a proteína do leite parece ter contribuído mais para o aumento da digestibilidade da dieta que o carboidrato presente no leite.

Este trabalho foi desenvolvido com o objetivo de avaliar a inclusão do LDP, em dietas isocalóricas contendo PCS, para leitões desmamados aos 21 dias de idade.

\section{Material e Métodos}

O experimento foi conduzido nas instalações do Sistema de Produção de Suínos da Embrapa Suínos e Aves, no período de 04 de setembro a 23 de outubro de 1997, e foram comparadas as seguintes dietas préiniciais, fornecidas do dia do desmame até 14 dias após: T1 - dieta testemunha, tendo o FS como principal fonte protéica; T2 - substituição de 30\% do FS da dieta testemunha por PCS; T3 - substituição de 30\% do FS da dieta testemunha por PCS e $20 \%$ por LDP; T4 - substituição de $50 \%$ do FS da dieta testemunha por PCS; T5 - substituição de 50\% do FS da dieta testemunha por PCS e $20 \%$ por LDP.

Todas as dietas experimentais fornecidas nos primeiros 14 dias após o desmame continham 14\% de lactose, proveniente do soro de leite em pó, da lactose cristalina e do LDP, e foram isocalóricas e isolisínicas (Tabela 1). As dietas foram formuladas com os valores de energia metabolizável dos ingredientes obtidos para leitões por BERTOL e LUDKE (1999). A composição nutricional das fontes protéicas utilizadas neste trabalho encontra-se na Tabela 2. Foi fornecida uma ração inicial, a mesma para todos os leitões dos 14 aos 35 dias após o desmame, a qual continha $10 \%$ de soro de leite em pó, $3250 \mathrm{kcal}$ EM e 1,26\% de lisina total. Os leitões receberam água e alimentação à vontade durante todo o período experimental.

Foram utilizados 160 leitões cruzados (macho Embrapa MS58 x fêmeas F1) desmamados aos 21 dias de idade, provenientes de dois grupos de desmame com 80 leitões cada e com intervalo de 14 dias entre ambos. Os leitões foram distribuídos por sexo dentro de baia, totalizando quatro baias de machos e quatro de fêmeas por tratamento, com quatro animais em cada baia. O delineamento experimental foi o de blocos casualizados de acordo com o peso inicial.

Foram abatidos 17 leitões (oito machos e nove fêmeas) no início do experimento, 40 leitões (20 machos e 20 fêmeas) 14 dias após o início do experimento e 39 leitões (19 machos e 20 fêmeas) 35 dias após o desmame (final da fase de creche), para avaliação da composição corporal. Após o abate, as meias-carcaças esquerdas, as vísceras vazias e o sangue foram congelados e, posteriormente, moídos separadamente. Foi formada uma amostra composta e representativa do corpo vazio por leitão abatido, juntando-se as meias carcaças esquerdas com $50 \%$ do peso das vísceras vazias e do sangue, para análise de matéria seca (MS), proteína bruta (PB) (N x 5,72), extrato etéreo (EE) e cinza. A matéria seca foi 
Rev. bras. zootec.

Tabela 1 - Composição centesimal das rações experimentais fornecidas de 0 a 14 dias após o desmame Table 1 - Percentage composition of the experimental diets fed from 0 to 14 days post-weaning

Ingredientes
Ingredient

Tratamento

\begin{tabular}{ccccc}
\multicolumn{5}{c}{ Treatment } \\
\hline FS(100\%) & FS(70\%) & FS(50\%) & FS(50\%) & FS(30\%) \\
& PCS(30\%) & PCS $(30 \%)$ & PCS(50\%) & PCS $(50 \%)$ \\
& & LDP(20\%) & & LDP(20\%) \\
\hline 40,904 & 44,169 & 45,818 & 46,274 & 47,662
\end{tabular}

Milho

33,475

Farelo de soja

10,000

Soybean meal

Soro de leite em pó

7,000

Lactose

Leite desnatado em pó

Dried skim milk

Proteína concentrada soja

High-protein soybean meal

Calcário

Limestone

Fosfato bicálcico

Óleo bruto de soja

Soybean oil

L-lisina

L-lysine $\mathrm{HCl}$

DL-metionina

DL-methionine

L-treonina

L-threonine

Sal comum

Salt

Promotor de crescimento

Growth promoter

Cloreto de colina $60 \%$

Choline cloride 60\%

Vitamin and mineral mix

Caulim

Inert material

Antioxidante

Antioxidant

Proteína bruta (\%)

Crude protein

$\operatorname{EM}(M E), \mathrm{kcal} / \mathrm{kg}$

Metabolizable energy

$\mathrm{Ca}(\%)$

P disponível (\%)

Available P

L-Lisina

L-Lysine

Metionina (\%)

Methionine

Metionina + cistina $(\%)$

Metionine + cystine

Treonina (\%)

Threonine

0,000

0,000

20,30

3300
Dicalcium phosphate

Mistura vitamínica e mineral

0,529

2,098

4,043

0,300

0,157

0,034

0,150

0,500

0,200

0,600

0,000

0,010

$\mathrm{FS}$ = farelo de so pó (dried skim milk). acid), 16 mg ac. fólico; (folic acid), 3 mg biotina (biotin), 6 ppm Se, 1998 mg Fe, 2499 mg Cu, 612 mg Mn, 1539 mg Zn e 17 mg I. 
1738

Tabela 2 - Composição nutricional das fontes protéicas utilizadas no experimento

Table 2 - Nutritional composition of the protein sources used in the experiment

\begin{tabular}{|c|c|c|c|}
\hline $\begin{array}{l}\text { Nutriente (\%) } \\
\text { Nutrient }\end{array}$ & FS & PCS & LDP \\
\hline$\overline{\mathrm{EM}(\mathrm{kcal} / \mathrm{kg})}$ & 3245 & 3740 & 3978 \\
\hline$E M$ & & & \\
\hline $\begin{array}{l}\text { Proteína bruta } \\
\text { Crude protein }\end{array}$ & 47,14 & 64,89 & 31,90 \\
\hline $\begin{array}{l}\text { Lisina } \\
\text { Lysine }\end{array}$ & 3,03 & 3,88 & 2,43 \\
\hline $\begin{array}{l}\text { Metionina } \\
\text { Methionine }\end{array}$ & 0,69 & 0,79 & 0,86 \\
\hline $\begin{array}{l}\text { Metionina+cistina } \\
\text { Met. }+ \text { cys. }\end{array}$ & 1,37 & 1,64 & 1,29 \\
\hline $\begin{array}{l}\text { Triptofano } \\
\text { Tryptophan }\end{array}$ & 0,67 & 0,79 & 0,41 \\
\hline $\begin{array}{l}\text { Treonina } \\
\text { Threonine }\end{array}$ & 1,85 & 2,67 & 1,50 \\
\hline $\begin{array}{l}\text { Histidina } \\
\text { Histidine }\end{array}$ & 1,17 & 1,64 & 0,82 \\
\hline $\begin{array}{l}\text { Isoleucina } \\
\text { Iloleucine }\end{array}$ & 2,07 & 2,91 & 2,09 \\
\hline $\begin{array}{l}\text { Leucina } \\
\text { Leucine }\end{array}$ & 3,53 & 4,73 & 3,16 \\
\hline $\begin{array}{l}\text { Fenilalanina+tirosina } \\
\text { Phenilalanine + tyrosine }\end{array}$ & 3,96 & 5,16 & 2,60 \\
\hline $\begin{array}{l}\text { Valina } \\
\text { Valine }\end{array}$ & 2,40 & 2,97 & 2,19 \\
\hline
\end{tabular}

$\mathrm{FS}$ = farelo de soja (soybean meal), $\mathrm{PCS}$ = proteína concentrada de soja (high-proteinsoybean meal), LDP = leite desnatado em pó (dried skim milk).

determinada por pré-secagem das amostras em estufa de ar forçado a $50^{\circ} \mathrm{C}$ e posterior secagem a $105^{\circ} \mathrm{C}$ (WINDHAM, 1995). O conteúdo de nitrogênio e o EE foram determinados no material seco, utilizando o método de Kjeldahl e o método de extração de Soxhlet, respectivamente, conforme (WINDHAM, 1995).

Nos leitões abatidos aos 14 dias também, foi avaliada a morfologia intestinal em quatro segmentos do intestino delgado: um fragmento do duodeno $(50 \mathrm{~cm}$ posterior ao piloro), dois do jejuno (fragmento $1 \mathrm{a} 2 \mathrm{~m}$ e o fragmento 2 a $4 \mathrm{~m}$ posterior ao local de coleta do fragmento do duodeno, respectivamente) e um do íleo (1 m anterior à válvula ileo-cecal). Em cada fragmento foram medidas a altura total da mucosa (AM), a altura das vilosidades (AV) e a profundidade da cripta (PC).

Os fragmentos de intestino foram coletados e processados da seguinte forma: foram amarradas as extremidades de cerca de $5 \mathrm{~cm}$ de cada porção do intestino e introduzido $10 \mathrm{~mL}$ do fixador (formalina $10 \%$ tamponada) no lúmem de cada fragmento. Em seguida, os fragmentos foram separados do restante do intestino e submergidos no mesmo fixador por 48 horas. Posteriormente, foram processados fragmentos transversais, com cerca de $2 \mathrm{~mm}$, pelo método de inclusão em parafina, e feitas três lâminas de cada fragmento em micrótomo rotativo, com 5 micras de espessura, as quais foram coradas pelo método da hematoxilina-eosina (LUNA, 1968) e examinadas em microscópio óptico. A altura das criptas e vilosidades (íntegras e bem orientadas) foi medida em três vilosidades e três criptas de cada lâmina, totalizando nove medidas em cada fragmento e 36 medidas em cada animal abatido. As medidas foram feitas usando-se microscópio óptico Carl Zeiss Jena (Jeneval), com objetiva $3,2 \mathrm{X}$, equipada com retículo (régua) previamente calibrado para medidas em micras. Foram feitas as médias das 36 medidas de cada animal, as quais foram utilizadas para análise estatística.

A taxa de deposição de proteína (TDP) e gordura (TDG) em cada fase foi calculada utilizando-se os valores de MS, PB e EE obtidos nos leitões abatidos em cada fase do experimento. Na análise de variância (SAS, 1996), foram considerados os efeitos de sexo, bloco, tratamento e grupo de desmame. As médias foram comparadas pelo teste t, a 10\% de significância.

\section{Resultados e Discussão}

A substituição de parte do FS por PCS em qualquer dos níveis testados, bem como a substituição de $20 \%$ do FS por LDP, não afetou $(\mathrm{P}>0,10)$ o desempenho dos leitões em nenhum dos períodos avaliados na fase de creche, com exceção da conversão alimentar (CA) no período dos 14 a 35 dias após o desmame (Tabela 3). Era esperado pior desempenho dos leitões que receberam a dieta cuja principal fonte de proteína era o FS, em função dos resultados obtidos por BERTOL et al. (1998), em que foram observados aumento do ganho de peso diário (GPD) e do consumo de ração diário (CRD) e melhor CA com a substituição de 50\% do FS da dieta de desmame por PCS. Neste experimento, os leitões que receberam a dieta cuja principal fonte de proteína foi o FS apresentaram GPD e CRD superiores aos que receberam dieta semelhante em BERTOL et al. (1998) e próximos ao verificado nos leitões alimentados com dieta contendo 50\% de substituição do FS por PCS. Foi verificado por BERTOL e LUDKE (1999) que os subprodutos da soja com maior grau de processamento, como a proteína texturizada de soja e a PCS, apresentaram digestibilidade da energia superior ao FS, porém, neste experimento, este fato foi compensado, mantendo-se o mesmo nível de 
Rev. bras. zootec.

Tabela 3 - Efeito de diferentes fontes protéicas na dieta de desmame sobre o peso médio e desempenho dos leitões após o desmame (médias \pm desvios-padrão)

Table 3 - Effect of different protein sources in the weaning diet on average weight and performance of piglets after weaning (means \pm standard error)

\begin{tabular}{|c|c|c|c|c|c|c|}
\hline \multirow{5}{*}{$\begin{array}{l}\text { Variáveis }^{1} \\
\text { Variables }\end{array}$} & \multicolumn{5}{|c|}{ Fonte protéica } & \multirow[t]{2}{*}{$\mathrm{P}^{2}$} \\
\hline & \multicolumn{5}{|c|}{ Protein source } & \\
\hline & FS & $\mathrm{FS}(70 \%)$ & $\mathrm{FS}(50 \%)$ & $\mathrm{FS}(50 \%)$ & FS $(30 \%)$ & \\
\hline & $(100 \%)$ & $\operatorname{PCS}(30 \%)$ & $\operatorname{PCS}(30 \%)$ & $\operatorname{PCS}(50 \%)$ & $\operatorname{PCS}(50 \%)$ & \\
\hline & & & $\operatorname{LDP}(20 \%)$ & & $\operatorname{LDP}(20 \%)$ & \\
\hline$\overline{\mathrm{PMI}(\mathrm{kg})}$ & $7,57 \pm 0,81$ & $7,72 \pm 0,94$ & $7,59 \pm 1,18$ & $7,70 \pm 1,04$ & $7,72 \pm 1,39$ & \\
\hline PM14 (kg) & $10,92 \pm 0,89$ & $11,03 \pm 0,97$ & $10,78 \pm 1,49$ & $10,79 \pm 1,39$ & $11,01 \pm 1,61$ & 0,87 \\
\hline \multirow[t]{2}{*}{ PM35 $(\mathrm{kg})$} & $22,83 \pm 1,46$ & $23,19 \pm 2,10$ & $22,94 \pm 2,60$ & $23,26 \pm 1,86$ & $23,13 \pm 2,59$ & 0,97 \\
\hline & \multicolumn{6}{|c|}{0 a 14 dias (from 0 to 14 days) } \\
\hline $\mathrm{GPD}(\mathrm{g})$ & $239 \pm 11$ & $237 \pm 33$ & $228 \pm 35$ & $220 \pm 32$ & $235 \pm 42$ & 0,65 \\
\hline $\mathrm{CRD}(\mathrm{g})$ & $336 \pm 23$ & $334 \pm 34$ & $311 \pm 43$ & $322 \pm 35$ & $327 \pm 44$ & 0,32 \\
\hline \multirow[t]{2}{*}{$\mathrm{CA}$} & $1,41 \pm 0,11$ & $1,42 \pm 0,13$ & $1,37 \pm 0,03$ & $1,47 \pm 0,10$ & $1,40 \pm 0,11$ & 0,43 \\
\hline & \multicolumn{6}{|c|}{14 a 35 dias (from 14 to 35 days) } \\
\hline $\mathrm{GPD}(\mathrm{g})$ & $567 \pm 46$ & $579 \pm 66$ & $579 \pm 63$ & $594 \pm 35$ & $577 \pm 54$ & 0,86 \\
\hline $\mathrm{CRD}(\mathrm{g})$ & $971 \pm 52$ & $980 \pm 115$ & $1001 \pm 149$ & $967 \pm 103$ & $920 \pm 126$ & 0,61 \\
\hline \multirow[t]{2}{*}{$\mathrm{CA}$} & $1,72 \pm 0,11^{\mathrm{ab}}$ & $1,70 \pm 0,11^{\mathrm{abc}}$ & $1,73 \pm 0,14^{\mathrm{a}}$ & $1,62 \pm 0,10^{\mathrm{cd}}$ & $1,59 \pm 0,13^{\mathrm{d}}$ & 0,05 \\
\hline & \multicolumn{6}{|c|}{0 a 35 dias (from 0 to 35 days) } \\
\hline GPD $(\mathrm{g})$ & $436 \pm 31$ & $442 \pm 44$ & $438 \pm 48$ & $445 \pm 33$ & $440 \pm 45$ & 0,99 \\
\hline CRD (g) & $717 \pm 39$ & $722 \pm 75$ & $725 \pm 100$ & $709 \pm 72$ & $683 \pm 89$ & 0,71 \\
\hline $\mathrm{CA}$ & $1,65 \pm 0,10$ & $1,64 \pm 0,11$ & $1,65 \pm 0,12$ & $1,59 \pm 0,08$ & $1,55 \pm 0,11$ & 0,17 \\
\hline
\end{tabular}

FS = farelo de soja (soybean meal), PCS= proteína concentrada de soja (high-protein soybean meal), LDP=leite desnatado em pó (dried skimmilk).

${ }^{1} \mathrm{PMI}=$ peso médio inicial (excluindo-se os leitões abatidos aos 14 dias) (average initial weight [excluding piglets slaughtered at 14 days]), PM14 = peso médio 14 dias pós-desmame (mean weight at 14 days post-weaning), PM35 = peso médio 35 dias pós-desmame (average weight at 35 days post-weaning), GPD = ganho de peso diário (daily weight gain), CRD = consumo de ração diário (daily feed intake), $\mathrm{CA}=$ conversão alimentar (feed:gain ratio).

${ }^{2} \mathrm{P}=$ probabilidade pelo teste $\mathrm{F}$ (probability by $\mathrm{F}$ test).

energia metabolizável em todas as dietas, por meio da suplementação comóleo. TURLINGTON et al.(1990) observaram que leitões desmamados aos 21 dias de idade e alimentados com dietas isocalóricas, contendo $32 \%$ de LDP apresentaram desempenho semelhante aos que receberam dietas com $16 \%$ de proteína concentrada de soja extrusada, semelhante à utilizada neste experimento. LI et al. (1991), comparando diversos subprodutos da soja em dietas isocalóricas para leitões desmamados aos 21 dias de idade, observaram que a proteína concentrada de soja extrusada proporcionou desempenho semelhante ao FS e ao LDP e o FS, menor desempenho que o LDP, no período de 0 a 14 dias após o desmame.

A altura da mucosa (AM) e a altura das vilosidades (AV) aos 14 dias após o desmame não foram afetadas $(\mathrm{P}>0,10)$ pela fonte protéica da dieta, porém a profundidade da cripta $(\mathrm{PC})$ foi reduzida $(\mathrm{P}<0,01)$ nos leitões que receberam as dietas contendo PCS, independente da inclusão de LDP (Tabela 4). A PC éindicativo do nível de hiperplasia das células epiteliais, o que está relacionado, entre outros fatores, com o grau de antigenicidade da dieta (HANCOCK et al., 1990b). A redução da PC no intestino delgado dos leitões que receberam as dietas com PCS está de acordo com o observado por LI et al. (1991a e b) e indica o menor nível de agressão à morfologia da parede intestinal por parte da PCS em comparação com o FS. No entanto, LI et al. (1991a e b) verificaram também menor $\mathrm{PC}$ e maior $\mathrm{AV}$, em função do uso do LDP, em comparação com o FS e a PCS e maior AV com o uso da PCS em comparação com o FS. Uma das possíveis causas das diferenças entre os resultados deste trabalho e o encontrado por LI et al. (1991a e b), com relação à morfologia intestinal, poderia ser o fato de que estes leitões foram abatidos aos 14 dias após o desmame (35 dias de idade) e, dessa forma, haveria mais tempo para recuperação parcial da estrutura da parede intestinal do que em LI et al. (1991a e b), no qual o abate foi feito sete dias 
BERTOL et al.

Tabela 4 - Efeito de diferentes fontes protéicas na dieta de desmame sobre a morfologia intestinal, em leitões (médias ajustadas \pm erro-padrão)

Table 4 - Effect of different protein sources in the weaning diet on intestinal morphology of piglets (adjusted means \pm standard error)

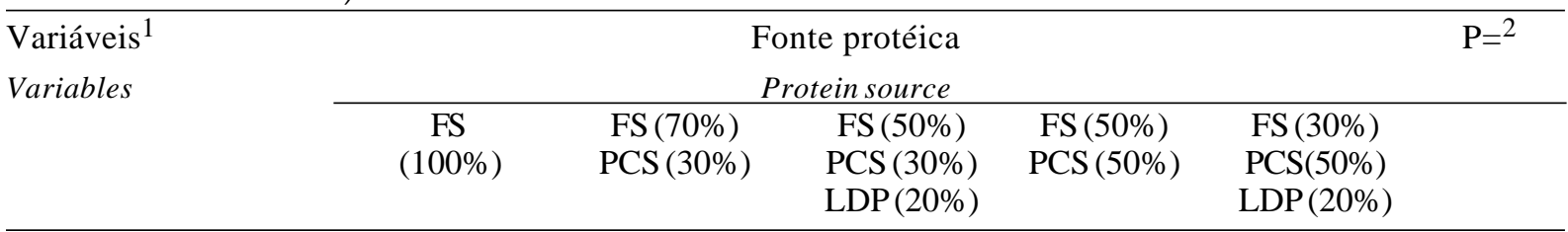

\begin{tabular}{|c|c|c|c|c|c|c|}
\hline \multirow[b]{2}{*}{$\mathrm{AM}(\mathrm{mm})$} & \multicolumn{5}{|c|}{$\begin{array}{l}\text { Morfologia intestinal aos } 14 \text { dias após o desmame } \\
\text { Intestinal morphology at } 14 \text { days post weaning }\end{array}$} & \multirow[b]{2}{*}{0,29} \\
\hline & $765 \pm 22$ & $738 \pm 19$ & $697 \pm 21$ & $745 \pm 21$ & $735 \pm 19$ & \\
\hline $\mathrm{AV}(\mathrm{mm})$ & $427 \pm 25$ & $441 \pm 22$ & $408 \pm 24$ & $466 \pm 24$ & $452 \pm 22$ & 0,49 \\
\hline $\mathrm{PC}(\mathrm{mm})$ & $339 \pm 13^{a}$ & $297 \pm 11^{b}$ & $289 \pm 12^{b}$ & $279 \pm 12^{\mathrm{b}}$ & $283 \pm 11^{b}$ & 0,01 \\
\hline
\end{tabular}

FS = farelo de soja (soybean meal), PCS= proteína concentrada de soja (high-protein soybean meal), LDP = leite desnatado em pó (dried skimmilk).

$1 \mathrm{AM}=$ altura da mucosa (mucous height), $\mathrm{AV}=$ altura das vilosidades (villus height), $\mathrm{PC}=$ profundidade da cripta (crypt depth).

$2 \mathrm{P}=$ probabilidade pelo teste $\mathrm{F}$ (Probability by $\mathrm{F}$ test).

após o desmame (aos 28 dias de idade). Além disso, LI et al. (1991a e b) substituíram totalmente o FS da dieta por PCS ou por LDP, enquanto neste trabalho a substituição foi parcial. Entretanto, LI et al. (1991b) e HANCOCK et al. (1990b) verificaram também que há relação positiva entre a AV no intestino delgado e a taxa de crescimento em leitões. Como o ganho de peso não foi afetado pela fonte protéica neste trabalho, é possível também que a AV não tenha sido realmente influenciada no período inicial após o desmame.

A composição corporal, bem como a TDP e a TDG, não foi afetada $(\mathrm{P}>0,10)$ pelos tratamentos em nenhum dos períodos avaliados (Tabela 5). Estes resultados, aliados aos dados de desempenho, indicam que não houve diferença no aproveitamento dos aminoácidos e da energia das diferentes dietas, uma vez que o consumo de ração também foi semelhante entre os tratamentos. A composição corporal do leitões abatidos no início do experimento foi a seguinte: $33,33 \%$ de MS, $53,75 \%$ PB, 38,81\% EE e 7,44\% cinzas na MS. Aos 14 dias após o desmame, o conteúdo médio de EE havia reduzido para $32,99 \%$ do corpo vazio e a TDG no período de 0 a 14 dias após o desmame foi negativa (Tabela 5). Resultados semelhantes foram obtidos por CLOSE e STANIER (1984a), em diferentes condições de ambiente (temperatura) e alimentação. A perda de gordura corporal no período inicial após o desmame é provocada provavelmente pelo estresse, pelo baixo consumo de alimento neste período e pelo baixo nível de energia da ração em comparação com a energia contida no leite da porca. Nos primeiros dias após o desmame, o consumo de ração foi muito baixo e ficou aquém do necessário para mantença dos leitões (Tabela 6). A necessidade de energia para mantença dos suínos, segundo NRC (1998), é de $106 \mathrm{kcal} \mathrm{EM/kg}$ peso corporal ${ }^{0,75} / \mathrm{dia}$ ou $110 \mathrm{kcal} \mathrm{ED} / \mathrm{kg}^{0,75}$ / dia, em condições de conforto ambiental. Em se tratando de uma ração com 3300 kcal EM, como a que foi fornecida nos primeiros 14 dias após o desmame neste experimento, os leitões teriam que consumir no mínimo $148 \mathrm{~g}$ por dia para atingir os seus requerimentos diários de mantença, o que foi obtido somente a partir do terceiro dia após o desmame. Após o período crítico inicial, a reserva de gordura corporal aumentou, conforme pode ser observado pela porcentagem de EE corporal aos 35 dias após o desmame e pela TDG no período de 14 a 35 dias. A TDP foi menos afetada pelo desmame, mantendo-se positiva mesmo no período inicial após o desmame. De acordo com CLOSE e STANIER (1984b), a deposição de gordura é muito dependente da temperatura ambiente e do consumo de energia, enquanto a deposição de proteína é muito menos afetada por estes fatores. 
Rev. bras. zootec.

Tabela 5 - Efeito de diferentes fontes protéicas na dieta de desmame sobre a composição corporal e taxa de deposição de tecidos, em leitões (médias ajustadas \pm erro-padrão)

Table 5 - Effect of different protein sources in the weaning diet on the body composition and tissue deposition rate of piglets (adjusted means \pm standard error)

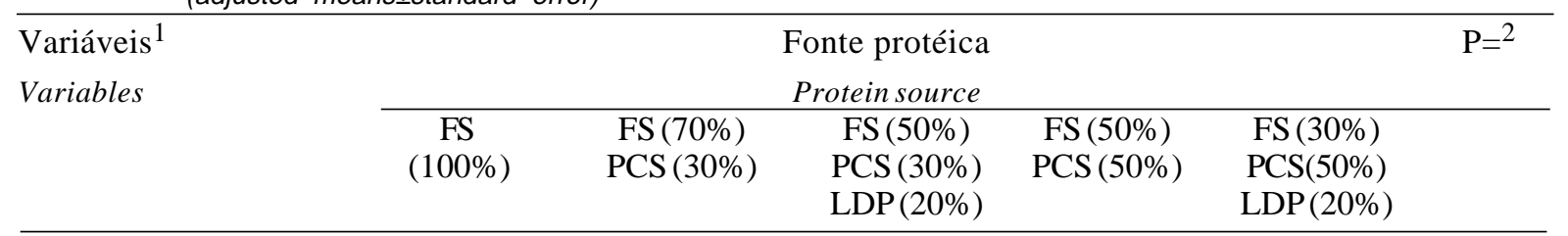

Composição corporal aos 14 dias após o desmame

Body composition at 14 days post weaning

\begin{tabular}{lcccccc}
\hline PV, kg & $10,29 \pm 0,28$ & $9,87 \pm 0,28$ & $9,89 \pm 0,28$ & $10,00 \pm 0,28$ & $10,33 \pm 0,28$ & 0,66 \\
MS, \% & $26,91 \pm 0,65$ & $27,58 \pm 0,65$ & $27,05 \pm 0,65$ & $27,70 \pm 0,65$ & $26,49 \pm 0,65$ & 0,49 \\
PB, \% & $58,19 \pm 0,54$ & $57,93 \pm 0,54$ & $58,84 \pm 0,54$ & $57,49 \pm 0,54$ & $58,42 \pm 0,58$ & 0,49 \\
EE, \% & $32,83 \pm 0,75$ & $33,69 \pm 0,75$ & $32,18 \pm 0,75$ & $33,51 \pm 0,75$ & $32,72 \pm 0,81$ & 0,62 \\
CZA, \% & $8,99 \pm 1,37$ & $8,38 \pm 1,06$ & $8,98 \pm 1,15$ & $9,00 \pm 1,01$ & $8,66 \pm 1,32$ & 0,71 \\
TDP0-14, g & $18,68 \pm 2,88$ & $14,48 \pm 2,88$ & $15,91 \pm 2,88$ & $13,98 \pm 2,88$ & $14,81 \pm 3,10$ & 0,79 \\
TDG0-14,g & $-4,07 \pm 2,83$ & $-5,01 \pm 2,83$ & $-7,89 \pm 2,83$ & $-5,44 \pm 2,83$ & $-6,98 \pm 3,06$ & 0,88 \\
\hline
\end{tabular}

Composição corporal aos 35 dias

Body composition at 35 days

\begin{tabular}{lllllll}
\hline PV, kg & $21,43 \pm 0,84$ & $20,61 \pm 0,78$ & $21,04 \pm 0,77$ & $21,57 \pm 0,77$ & $20,94 \pm 0,77$ & 0,91 \\
MS, \% & $29,24 \pm 0,53$ & $29,50 \pm 0,49$ & $28,72 \pm 0,49$ & $28,39 \pm 0,49$ & $28,64 \pm 0,49$ & 0,50 \\
PB, \% & $42,70 \pm 1,35$ & $46,24 \pm 1,26$ & $44,83 \pm 1,35$ & $45,66 \pm 1,25$ & $45,71 \pm 1,25$ & 0,37 \\
EE, \% & $46,44 \pm 1,61$ & $42,55 \pm 1,51$ & $43,90 \pm 1,61$ & $43,28 \pm 1,50$ & $42,98 \pm 1,50$ & 0,45 \\
CZA, \% & $10,84 \pm 1,06$ & $11,19 \pm 1,14$ & $11,25 \pm 0,79$ & $11,06 \pm 0,98$ & $11,31 \pm 1,31$ & 0,92 \\
TDP0-35,g & $37,42 \pm 2,63$ & $39,98 \pm 2,45$ & $38,40 \pm 2,63$ & $40,27 \pm 2,45$ & $38,50 \pm 2,45$ & 0,93 \\
TDG0-35,g & $54,74 \pm 5,59$ & $46,06 \pm 5,20$ & $50,21 \pm 5,59$ & $48,42 \pm 5,15$ & $47,00 \pm 5,16$ & 0,81 \\
\hline
\end{tabular}

$\mathrm{FS}=$ farelo de soja (soybean meal), $\mathrm{PCS}=$ proteína concentrada de soja (high-protein soybean meal), LDP= leite desnatado em pó (dried skim milk).

$1 / \mathrm{PV}=$ peso vivo (live weight), MS = matéria seca (dry matter), $\mathrm{PB}=$ proteína bruta (crude protein), $\mathrm{EE}=$ extrato etéreo (ether extract), CZA = cinza (ash), TDP0-14 e TDP0-35 = taxa de deposição diária de proteína corporal dos 0 aos 14 e dos 0 aos 35 dias (daily body protein deposition rate from 0 to 14 and from 0 to 35 days), TDG0-14 e TDG0-35 = taxa de deposição diária de gordura corporal dos 0 aos 14 e dos 0 aos 35 dias (daily body fat deposition rate from 0 to 14 and from 0 to 35 days).

${ }^{2 /} \mathrm{P}=$ probabilidade pelo teste $\mathrm{F}$ (probability by $\mathrm{F}$ test).

Tabela 6 - Consumo diário médio de ração $(\mathrm{g})$ por leitão em cada tratamento, do 1 ao 13o dia após o desmame Table 6 - Average daily intake $(\mathrm{g})$ per piglet in each treatment, from 1 to $13^{\text {th }}$ day post-weaning

\begin{tabular}{lcccccc}
\hline $\begin{array}{l}\text { Dia pós-desmame } \\
\text { Post weaning day }\end{array}$ & \multicolumn{3}{c}{$\begin{array}{c}\text { Fonte protéica } \\
\text { Protein source }\end{array}$} & $\begin{array}{c}\text { Média } \\
\text { Mean }\end{array}$ \\
\cline { 2 - 5 } & FS & FS (70\%) & FS (50\%) & FS (50\%) & FS (30\%) \\
PCS (100\%) & PCS (30\%) & PCS (30\%) & PCS (50\%) & PCS(50\%) \\
LDP(20\%) & \\
\hline 1 & 18 & 16 & 8 & 12 & 22 & 15 \\
2 & 27 & 53 & 59 & 39 & 24 & 40 \\
3 & 166 & 181 & 146 & 142 & 139 & 155 \\
4 & 213 & 224 & 152 & 171 & 187 & 189 \\
5 & 209 & 233 & 168 & 190 & 186 & 197 \\
6 & 242 & 273 & 202 & 222 & 220 & 232 \\
7 & 278 & 317 & 284 & 283 & 282 & 289 \\
8 & 359 & 366 & 365 & 358 & 387 & 367 \\
9 & 473 & 434 & 431 & 447 & 459 & 449 \\
10 & 461 & 493 & 473 & 509 & 510 & 489 \\
11 & 563 & 522 & 532 & 565 & 561 & 549 \\
12 & 623 & 537 & 553 & 539 & 554 & 561 \\
13 & 642 & 600 & 567 & 599 & 637 & 609 \\
\hline
\end{tabular}

$\mathrm{FS}=$ farelo de soja (soybean meal), PCS = proteína concentrada de soja (high-protein soybean meal), LDP = leite desnatado em pó (driedskim milk). 


\section{Conclusões}

A substituição parcial do farelo de soja pela proteína concentrada de soja, associada ou não com o leite desnatado em pó na dieta de desmame, não influenciou o desempenho nem a composição corporal de leitões desmamados aos 21 dias de idade.

O aproveitamento dos aminoácidos foi semelhante entre as dietas, independente da substituição parcial da fonte protéica.

A proteína concentrada de soja apresentou menor atividade antigênica do que o farelo de soja.

\section{Referências Bibliográficas}

BERTOL, T.M., LUDKE, J.V. 1999. Determinação dos valores de energia e do balanço de nitrogênio de alguns alimentos para leitões na fase inicial. Rev. bras. zootec., 28(6):1279-1287.

BERTOL, T.M., MORES, N., LUDKE, J.V. et al. Proteínas da soja processadas por diferentes métodos em dietas para desmame de leitões. In: REUNIÃO ANUAL DA SOCIEDADE BRASILEIRA DE ZOOTECNIA, 35, 1998, Botucatu. Anais... Botucatu: SBZ, 1998, v.4, p.345-347.

CLOSE, W.H., STANIER, M.W. 1984a. Effects of plane of nutrition and environmental temperature on the growth and development of the early-weaned piglet. 1. Growth and body composition. Anim. Prod., 38:211-220.

CLOSE, W.H., STANIER, M.W. 1984b. Effects of plane of nutrition and environmental temperature on the growth and development of the early-weaned piglet. 2. Energy metabolism. Anim. Prod., 38:221-231.

FRIESEN, K.G., NELSSEN, J.L., BEHNKE, K.C. 1992. Effect of extrusion parameters. Feed International, 13(9):50-55.

FRIESEN, K.G., NELSSEN, J.L., GOODBAND, R.D. et al. 1993. The effect of moist extrusion of soy products on growth performance and nutrient utilization in the earlyweaned pig. J. Anim. Sci., 71(8):2099-2109.

HANCOCK, J.D., PEO JR. E.R., LEWIS, A.J. et al. 1990a. Effects of ethanol extraction and duration of heat treatment of soybean flakes on the utilization of soybean protein by growing rats and pigs. J. Anim. Sci., 68(10):3233-3243.

HANCOCK, J.D., PEO JR. E.R., LEWIS, A.J. et al. 1990b. Effects of ethanol extraction and heat treatment of soybean flakes on function and morphology of pig intestine. J. Anim. Sci., 68(10):3244-3251.
LI, D.F., NELSSEN, J.L., REDDY, P.G. et al. 1991b. Measuring suitability of soybean products for early-weaned pigs with immunological criteria. J. Anim. Sci., 69(8):3299-3307.

LI, D.F., NELSSEN, J.L., REDDY, P.G. et al. 1991b. Interrelationship between hypersensivity to soybean proteins and growth performance in early-weaned pigs. J. Anim. Sci., 69(10):4062-4069.

LUNA, L.G. 1968. Manual of histologic staining methods of the Armed Forces Institute of Pathology. 3.ed., New York: McGraw-Will. 258p.

NATIONAL RESEARCH COUNCIL - NRC. 1998. Nutrients requirements of swine. 10. ed. Washington: National Academy of Science. 189p. (Nutrient Requirements of Domestic Animals, 2).

PARTRIDGE, G.G., GILL, B.P. 1993. New approaches with pig weaner diets. In: GARNSWORTHY, P.C., COLE, D.J.A. (Eds.) Recent Advances in animal nutrition. Nottingham: University Press, Cap. 14. p.221-248.

SAS INSTITUTE INC. 1996. SAS System for Windows, release 6.12. Cary, NC, USA. 01 CD-ROM.

TURLINGTON, W.H., ALLEE, G.L., NELSSEN, J.L. 1989. Effects of protein and carbohydrate sources on digestibility and digesta flow rate in weaned pigs fed a high-fat diet. J. Anim. Sci., 67(9):2333-2340.

TURLINGTON, W.H., POLLMANN, D.S., ENDRES, J.G. et al. 1990a. Soy protein concentrates: an alternative to milk proteins. Feedstuffs, 62(37):16-18.

TURLINGTON, W.H., POLLMANN, D.S., COALSON, J.A. et al. 1990b. Nutritive value of soy protein concentrate in starter pig diets. J. Anim. Sci., 68:357 (suppl. 1).

WILSON, R.H., LEIBHOLZ, J. 1981. Digestion in the between 7 and $35 \mathrm{~d}$ of age 3 . The digestion of nitrogen in pigs given milk and soya-bean proteins. Brit. J. Nutr., 45:337-346.

WINDHAM, W.R. 1995. Animal feed. In: CUNNIF, P. (Ed.) Official methods of analysis of AOAC International, 16.ed. Arlington AOAC International, v.1, cap.4, p.1-30.

Recebido em: 23/12/99

Aceito em: 04/04/00 